Jurnal Indobiosains. Vol. 3 No. 1. Edisi Februari 2021

https://jurnal.univpgri-palembang.ac.id/index.php/biosains

\title{
KOMPOSISI DAN STRUKTUR KOMUNITAS GULMA PADA PERKEBUNAN KELAPA SAWIT (Elaeis guineensis Jacq.) DI DAERAH ARAU BINTANG KOTA BENGKULU
}

\author{
Putri Nur Febriani Nasution ${ }^{1 *}$, Dewi Rosanti ${ }^{2}$, Inka Dahlianah ${ }^{3}$ \\ ${ }^{1,2,3}$ Program Studi Biologi, Fakultas Sains dan Teknologi \\ Universitas PGRI Palembang \\ *e-mail: putrinurfebrianinasution@gmail.com
}

\begin{abstract}
Research on the composition and structure of weed communities in oil palm plantations in the Arau Bintang area of Bengkulu City was carried out in March-July 2020 aimed at analyzing the composition and structure of weed communities on oil palm plantations in the Arau Bintang area of Bengkulu City. The research used a survey method. Data were collected by observing the observed weed species. The results showed that the weeds found were 2 Divisio, 4 Class, 7 Order, 9 Familia, 15 Genus, 17 species, namely Borreria latifolia, Melastoma malabathricu, Stenochlaena palustris, Ageratum conyzoides, Mikania micrantha, Cyperus kyllingia, Cyperus rotundus, Cyperus compresus, Digitaria ciliaris, Rhynchospora corymbosa, Pueraria phaseoloides, Clidemia hirta, Axonopus compresus, Cynodon dactylon, Paspalum conjugatum, Sporobolus diander, Nephrolepis bisserata. The highest relative density (KR) was owned by Ageratum conyzoides (bandotan) with a value of $24.80 \%$. The lowest density was seen in the Sporobolus species with a density value of 0.4 individuals $/ \mathrm{m} 2$ and a relative density of $0.9 \%$. The highest relative frequency is owned by 9 species, namely Ageratum conyzoides, Axonopus compresus, Pueraria phaseoloides, Cynodon dactylon, Borreria latifolia, Mikania micrantha, Rhynchospora corymbosa, Clidemia hirta and Sporobolus diande, each with the highest value of $100 \%$, while the lowest frequency value is Stenochlaena. palustris with a frequency value of 0.4 and a relative frequency of $2.73 \%$. The highest Importance Value Index (INP) is Ageratum conyzoides, namely 31.64. The species with the lowest IVI value was Stenochlaena palustris with an IVI value of $4.42 \%$.
\end{abstract}

Keywords: Weeds, Quadratic Method, Composition, Community Structure

\begin{abstract}
ABSTRAK
Penelitian tentang komposisi dan struktur komunitas gulma di perkebunan kelapa sawit di daerah Arau Bintang Kota Bengkulu telah dilaksanakan pada bulan Maret-Juli 2020 bertujuan untuk menganalisis komposisi dan struktur komunitas gulma pada perkebunan kelapa sawit di daerah Arau Bintang Kota Bengkulu. Penelitian mengunakan metode survey. Data dikumpulkan dengan melakukan observasi terhadap spesies gulma yang diamati. Hasil penelitian menunjukkan bahwa gulma yang ditemukan sebanyak 2 Divisio, 4 Class, 7 Ordo, 9 Familia, 15 Genus, 17 Spesies yaitu Borreria latifolia,
\end{abstract}


Melastoma malabathricu, Stenochlaena palustris, Ageratum conyzoides, Mikania micrantha, Cyperus kyllingia, Cyperus rotundus, Cyperus compresus, Digitaria ciliaris, Rhynchospora corymbosa, Pueraria phaseoloides, Clidemia hirta, Axonopus compresus, Cynodon dactylon, Paspalum conjugatum, Sporobolus diander, Nephrolepis bisserata. Kerapatan Relatif (KR) yang tertinggi dimiliki Ageratum conyzoides (bandotan) dengan nilai 24,80\%, Kerapatan yang terendah terlihat pada spesies Sporobolus dengan nilai kerapatan 0,4 individu/ $\mathrm{m}^{2}$ dan kerapatan realtif $0,9 \%$. Frekuensi relatif tertinggi dimiliki 9 spesies yaitu Ageratum conyzoides, Axonopus compresus, Pueraria phaseoloides, Cynodon dactylon, Borreria latifolia, Mikania micrantha, Rhynchospora corymbosa, Clidemia hirta dan Sporobolus diande, masing-masing dengan nilai tertinggi 100\%, Sedangkan nilai frekuensi yang terendah yaitu Stenochlaena palustris dengan nilai frekuensi 0,4 dan frekuensi relatif 2,73\%. Indeks nilai penting (INP) yang tertinggi adalah Ageratum conyzoides yaitu 31,64. Spesies yang memiliki nilai INP terendah adalah Stenochlaena palustris dengan nilai INP 4,42\%. .

Kata kunci: Gulma, Metode kuadrat, Komposisi, Struktur Komunitas

\section{PENDAHULUAN}

Komunitas andalan salah satu di Provinsi Bengkulu adalah kelapa sawit (Elaeis guinensis Jacq). Luas areal perkebunan kelapa sawit di Provinsi Bengkulu adalah 165.276 ha. Perkembangan luas perkebunan kelapa sawit di Provinsi Bengkulu termasuk sangat cepat. Pada akhir 2008 luas areal perkebunan rakyat mencapai 100.865 ha, jauh melebihi perkebunan swasta seluas 61.266 ha (Sugiarto, 2011).

Perkebunan kelapa sawit telah memberikan peran penting pada perekonomian dan pembangunan nasional. Perkebunan kelapa sawit juga mampu menciptakan lapangan pekerjaan sehingga menambah kesejahteraan masyarakat. Menurut Pahan (2013), sebanyak 85\% lebih pasar dunia kelapa sawit dikuasai Indonesia dan Malaysia. Kelapa sawit merupakan tanaman monokotil yang memiliki akar serabut, akar primer terus berkembang menjadi $15 \mathrm{~cm}$ yang tumbuh secara vertikal kedalam tanah. Tanaman kelapa sawit ini tidak mempunyai batang yang bercabang sehingga mencapai 24

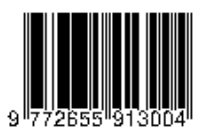

E IISN: 2655-9137 meter, di batangnya terdapat pangkal pelepah-pelepah daun yang melekat kokoh dan sukar terlepas walaupun sudah mati (Suwarto, 2010).

Gulma merupakan tumbuhan yang mengganggu atau merugikan kepentingan manusia sehingga manusia berusaha untuk mengendalikannya. Kerugian yang diakibatkan oleh gulma tidak terlihat secara langsung. Kompetisi yang diakibatkan oleh gulma dapat terjadi di atas permukaan tanah, kompetisinya dapat berupa memperebutkan ruang tumbuh, cahaya, dan oksigen dan di dalam tanah kompetisinya dalam memperebutkan unsur hara, dan air (Sembodo, 2010). Kehadiran gulma di perkebunan kelapa sawit berpengaruh negatif terhadap tanaman kelapa sawit yaitu menyebabkan terjadinya kompetisi antara gulma dengan kelapa sawit. Kompetisi ini dapat menyebabkan penurunan pertumbuhan, kuantitas dan kualitas produksi tandan segar (TBS). Kerugian yang diakibatkan oleh gulma tidakterlihat secara langsung akan tetapi terakumulasi pada produksi, akibat dari 
terhambatnya pertumbuhan akibat gangguan dari gulma (Dahlianah,2019).

Gulma di kebun sawit bersifat tidak semuanya merugikan untuk tanaman budidaya maupun lingkungan. Beberapa jenis gulma seperti Aregatum conyzoides dapat dimanfaatkan sebagai penutup tanah; Borreria latifolia juga bisa digunakan sebagai penutup tanah serta tidak melakukan kompetisi (Mangoensoekarjo \& Soejono, 2015). Nephrolepis bisserata yang termasuk jenis pakuan juga dimanfaatkan sebagai pengganti tanaman kacangan di bawah tanaman kelapa sawit menghasilkan karena kemampuannya hidup di bawah naungan, dapat menjadi penutup tanah, dan menjaga kelembaban tanah sehingga menurunkan laju evaporasi (Ariyanti et al., 2015).Berdasarkan uraian di atas perlu dilakukan penelitian tentang gulma pada perkebunan kelapa sawit, sebagai informasi keberadaan gulma-gulma di sana, baik nilai pentingnya maupun keanekaragamannya khususnya di daerah Arau Bintang Kota Bengkulu.

\section{BAHAN DAN METODE}

Penelitian ini telah dilaksanakan pada bulan Maret sampai Juli 2020. Lokasi penelitian dilakukan di daerah perkebunan Arau Bintang Kota Bengkulu. Peralatan yang digunakan dalam penelitian ini yaitu, alat tulis, gunting, meteran/penggaris, Patok kayu, alat penghitung. sedangkan bahan yang digunakan vegetasi tumbuhan pada perkebunan kelapa sawit di daerah arau bintang kota bengkulu.

Penelitian menggunakan metode survey, dimana pengambilan sampel dilakukan dengan metode kuadrat dengan menentukan 5 plot berukuran $2 \mathrm{~m}$ x $2 \mathrm{~m}$ dalam areal petak contoh utama berukuran
$100 \mathrm{~m}$ x $100 \mathrm{~m}$. Data dikumpulkan dengan melakukan observasi atau pengamatan langsung terhadap spesies gulma yang diamati.

Data yang diperoleh kemudian dianalisis secara kuantitatif dengan menghitung menggunakan rumus menurut (Mueller-Doumbois, 1974 dalam Dahlianah, 2019) sebagai berikut :

$$
\begin{aligned}
& \mathrm{KM}=\frac{\text { jumlah } \text { individu suatu jenis }}{\text { luas petak pengamatan }} \\
& \mathrm{KR}=\frac{\text { Kerapatan suatu jenis }}{\text { Kerapatan seluruh jenis }} \times 100 \% \\
& \mathrm{FM}=\frac{\text { jumlah petak yang ditempati suatu }}{\text { jumlah semua petak pengamatan }} \\
& \mathrm{FR}= \\
& \frac{\text { Frekuensi mutlak dalam suatu jenis }}{\text { Frekuensi seluruh jenis }} \mathrm{X} 100 \%
\end{aligned}
$$

INP $=$ Kerapatan Relatif + Frekuensi Relatif

\section{HASIL DAN PEMBAHASAN}

Hasil penelitian yang telah dilakukan di areal perkebunan kelapa sawit (Elaeis guineensis Jacq.) yang berumur 14 tahun di Arau Bintang Kota Bengkulu ditemukan 17 spesies gulma yang disajikan dalam Tabel 1 di bawah ini : 
Tabel 1. Analisis data gulma pada perkebunan kelapa sawit (Elaeis guineensis) yang berumur 14 tahun di Arau Bintang Kota Bengkulu.

\begin{tabular}{|c|l|c|r|r|r|r|r|}
\hline \multirow{2}{*}{ No } & Species & $\begin{array}{c}\text { ind } \\
\left(\mathrm{ind} / \mathrm{m}^{2}\right)\end{array}$ & $\begin{array}{r}\text { KM } \\
\left(\mathrm{Ind} / \mathrm{m}^{2}\right)\end{array}$ & $\begin{array}{c}\text { KR } \\
\%\end{array}$ & $\begin{array}{c}\text { FM } \\
\left(\mathrm{Ind} / \mathrm{m}^{2}\right.\end{array}$ & $\begin{array}{c}\text { FR } \\
(\%)\end{array}$ & \multicolumn{1}{c|}{ INP } \\
\hline 1 & Stenochlaena palustris & 15 & 0.75 & 1.69 & 0.4 & 2.73 & 4.42 \\
\hline 2 & Nephrolepis bisserata & 46 & 2.3 & 5.19 & 0.8 & 5.47 & 4.42 \\
\hline 3 & Cyperus compresus & 17 & 0.85 & 1.91 & 0.8 & 5.47 & 7.44 \\
\hline 4 & Cyperus kyllingia & 34 & 1.7 & 3.85 & 0.6 & 4.1 & 7.93 \\
\hline 5 & Cyperus rotundus & 36 & 1.8 & 4.05 & 0.8 & 5.47 & 9.52 \\
\hline 6 & Rhynchospora corymbos & 15 & 0.75 & 1.69 & 1 & 6.84 & 8.53 \\
\hline 7 & Axonopus compresus & 215 & 10.75 & 24.23 & 1 & 6.84 & 31.07 \\
\hline 8 & Cynodon dactylon & 55 & 2.75 & 6.2 & 1 & 6.8 & 13.04 \\
\hline 9 & Digitaria ciliaris & 28 & 1.4 & 3.15 & 0.8 & 5.47 & 8.62 \\
\hline 10 & Paspalum conjugatum & 12 & 0.6 & 1.36 & 0.6 & 4.1 & 5.45 \\
\hline 11 & Sporobolus diander & 8 & 0.4 & 0.9 & 1 & 6.84 & 7.74 \\
\hline 12 & Ageratum conyzoides & 220 & 11 & 24.8 & 1 & 6.84 & 31.64 \\
\hline 13 & Mikania micrantha & 33 & 1.65 & 3.73 & 1 & 6.84 & 10.56 \\
\hline 14 & Pueraria phaseoloides & 63 & 3.15 & 7.1 & 1 & 6.84 & 13.94 \\
\hline 15 & Melastoma malabathricu & 30 & 1.5 & 3.38 & 0.8 & 5.47 & 8.85 \\
\hline 16 & Clidemia hirta & 10 & 0.5 & 1.13 & 1 & 6.84 & 7.96 \\
\hline 17 & Borreria latifolia & 50 & 2.5 & 5.64 & 1 & 6.84 & 12.47 \\
\hline & JUMLAH & 887 & 44.35 & 100 & 14.6 & 100 & 200 \\
\hline
\end{tabular}

Gulma yang terdapat di perkebunan kelapa sawit pada Tabel 1 menunjukkan gulma yang ditemukan sebanyak 17 spesies, yaitu Borreria latifolia (Rumput setawar), Melastoma malabathricu (seduduk), Stenochlaena palustris (paku udang), Ageratum conyzoides (bandotan), Mikania micrantha (sembung rambat), Cyperus kyllingia (rumput teki), Cyperus rotundus (rumput teki), Cyperus compresus (rumput teki), Digitaria ciliaris (rumput kebo), Rhynchospora corymbosa (rumput sendayan, Pueraria phaseoloides (kacang ruji), Clidemia hirta (harendong), Axonopus compresus (rumput pahit), Cynodon dactylon (rumput grinting),

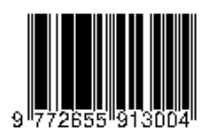

E IISN: 2655-9137
Paspalum conjugatum (jukut pahit), Sporobolus diander, Nephrolepis bisserata. Secara taksonomi spesies-spesies ini terdiri dari 2 Divisio yaitu Divisio Pteridophyta dan Spermatophyta 4 kelas yaitu Filicinae, Pteridopsida Monocotyledoneae, Dicotyledonaeae. Kondisi di lapangan terlihat tajuk kelapa sawit di perkebunan ini saling menutupi sehingga penerimaan intensitas cahaya yang diterima rendah, termasuk tumbuhan paku-pakuan yang menyukai kelembaban sehinggat tumbuh subur. Keadaan seperti ini mengakibatkan hanya gulma tertentu yang dapat tumbuh di intensitas cahaya rendah ( Muhamed, 2015).

Pada nilai kerapatan yang tertinggi ini yaitu Ageratum conyzoides(bandotan) 
dengan 11,00 ind $/ \mathrm{m} 2$ dan kerapatan relatif $24,80 \%$ karena berkembang biak dengan cara biji atau dikotil, perkembangbiakan gulma ini sangat cepat sedikitnya 2 bulan Ageratum conyzoides sudah mulai berkembangbiak dan siklus hidup Ageratum conyzoides bisa mencapai tahunan. Biji Ageratum conyzoides dapat tumbuh sekitar $50 \%$ ketika terkena sinar matahari dikarenakan biji sangat memerlukan sinar matahari untu berkecambah (Kamboj dan Saluja, 2010).

Kerapatan yang terendah terlihat pada spesies Sporobolus dengan nilai kerapatan $0,4 \mathrm{individu} / \mathrm{m}^{2}$ dan kerapatan realtif $0,9 \%$. Hal ini menunjukkan bahwa Sporobolus diander tidak menunjukkan pertumbuhan dengan baik dikarenakan kurang mendapatkan intensitas cahaya sehingga kalah bersaing dengan tumbuhan lain. Spesies gulma Sporobolus diander tersebut dapat berkembang biak secara generatif dengan biji, maupun secara vegetatif dengan rimpang, umbi dan tunas (Suryaningsih et al., 2010)

Frekuensi gulma pada perkebunan kelapa sawit (Elaeis guineensis Jacq.) di daerah arau bintang kota bengkulu yang tertinggi spesiesnya, Ageratum conyzoides, Axonopus compresus, Pueraria phaseoloides, Cynodon dactylon, Borreria latifolia, Mikania micrantha, Rhynchospora corymbosa, Clidemia hirta, Sporobolus diande, dengan nilai frekuensi 1 dari 17 plot yang diamati di areal penelitian dengan nilai frekuensi relatif $6,84 \%$ di setiap spesies tersebut. Tingginya nilai frekuensi karena tumbuhan ini ditemukan di setiap petak pengamatan penelitian dan gulma ini mampu bersaing dalam mendapatkan nutrisi seperti air, sinar matahari dan unsur hara. Frekuensi relatif gulma atau persaingan gulma tergantung pada curah hujan, kondisi tanah, dan kerapatan gulma. Faisal et al., (2013) menyatakan bahwa secara fisik gulma bersaing dengan tumbuhan dalam hal pemanfaatan ruang, cahaya dan secara kimiawi dalam hal pemanfaatan air, nutrisi, gas-gas penting dalam proses alelopati.

Nilai frekuensi yang terendah yaitu, Cyperus compresus, Cyperus rotundus, Nephrolepis bisserata, Melastoma malabathricum, dan Digitaria ciliaris dengan nilai frekuensi rata-rata 0,8 dan nilai frekuensi relatif $5,47 \%$. Nilai frekuensi kedua yang terendah yaitu Cyperus kyllingia, Paspalum conjugatum dengan nilai frekuensi 0,6 dan frekuensi relatif $4,10 \%$ dan gulma Stenochlaena palustris dengan nilai frekuensi 0,4 dan frekuensi relatif $2,73 \%$. Sedikitnya spesies gulma areal plot penelitian diduga penyebarannya tidak merata, disebabkan spesies tersebut tidak mendapatkan unsur hara, serta sinar matahari yang cukup baik karena gulma tertutup oleh kenopi daun sehingga cahaya tidak sepenuhnya masuk dan kalah bersaing dengan gulma yang mendapatkan intensitas cahaya (Dahlianah, 2019).

Indeks nilai penting tertinggi dimiliki oleh Ageratum conyzoides yaitu $31,64 \%$. Hal ini disebabkan karena gulma mendapatkan unsur hara, nutrisi dan intensitas cahaya yang baik. Lebih lanjut menurut Palijama et al., (2012) Gulma dipengaruhi banyak faktor, beberapa diantaranya adalah kelembaban tanah dan intensitas cahaya. Kelembaban tanah pada pertanaman tahun tanaman yang lebih tua relatif lebih lembab dibandingkan dengan pertanaman tahun tanam yang lebih muda. Sehingga jumlah individu banyak Ageratum conyzoides tumbuh diseluruh petak pengamatan kemampuan dalam menempati sebagian besar lokasi pada penelitian dapat menunjukkan bahwa 
spesies ini memiliki kemampuan dalam beradaptasi dengan kondisi lingkungan.

\section{KESIMPULAN}

Hasil penelitian yang telah dilakukan tentang komposisi dan struktur gulma pada perkebunan tegakkan kelapa sawit (Elaeis guineensis Jacq.) di daerah Arau Bintang Kota Bengkulu didapatkan kesimpulan sebagai berikut :

1. Komposisi gulma pada perkebunan kelapa sawit ditemukan sebanyak 2 Divisio, 4 Class, 7 Ordo, 9 Familia, 15 Genus, 17 Spesies dan 887 individu.

2. Kerapatan Relatif (KR) yang tertinggi adalah Ageratum conyzoides (bandotan) dengan nilai $24,80 \%$, sedangkan yang terendah Sporobolus diander dengan nilai kerapatan $0,90 \%$. Frekuensi mutlak yang tertinggi yaitu spesies Ageratum conyzoides, Axonopus compresus, Pueraria phaseoloides, Cynodon dactylon, Borreria latifolia, Mikania micrantha, Rhynchospora corymbosa, Clidemia hirta, Sporobolus diande,masing-masing dengan nilai tertinggi $1,00 \mathrm{ind} / \mathrm{cm}^{2}$. Nilai frekuensi yang terendah yaitu Cyperus compresus, Cyperus rotundus, Nephrolepis bisserata, Melastoma malabathricum, dan gulma Stenochlaena palustris dengan nilai frekuensi 0,4 dan frekuensi relatif $2,73 \%$. Indeks nilai penting (INP) yang tertinggi adalah Ageratum conyzoides yaitu $31,64 \%$. dan terendah pada tumbuhan Stenochlaena palustris dan Nephrolepis bisserata dengan nilai INP $4,42 \%$.

\section{DAFTAR PUSTAKA}

Ariyanti, M., S. Yahya, K. Murtilaksono, Suwarto, dan H.H. Siregar. 2015. Study of the Growth of Neprolepis Bisserata Kuntze and its Utilization of cover crop under mature oil palm plantation. International Journal of Sciences: Basic and Applied Research 1 (19): 325-331

Dahlianah, I. 2019. Keanekaragaman Jenis Gulma di Perkebunan Kelapa Sawit Desa Manggaraya Kecamatan Tanjung Lago Kabupaten Banyuasin. Jurnal Indobiosains, 1(1).

Mangoensoekarjo, S dan A.T. Soejono. 2015. Ilmu Gulma dan Pengelolaan Pada Budidaya Perkebunan. Gadjah Mada University Press.Yogyakarta.

Mohamed, M. S dan I. A. Seman. 2012. Occurance of Common Weed in Immature Planting of Oil Palm Plantation in Malaysia. The Planer, Kuala Lumpur.

Rosanti, D. 2012. Taksonomi Gulma Pada Perkebunan Kacang Panjang Desa Sungai Pinang Kabupaten Banyuasin. Jurnal Sainmatika. 9(1): 9-1 hlm.

Sembodo, D. R. J. 2010. Gulma dan Pengelolaannya.Yogyakarta: Graha Ilmu.

Sugiarto. 2011. Kajian Peranan Sertifikasi Benih pada Usaha Penangkaran Benih dalam Mendukung Pembangunan di Bengkulu. Jurnal Agricultural Scince. Vol. 1 (2) : 86$93 \mathrm{hlm}$. 
Komposisi dan Struktur Komunitas.., Putri Nur Febriani Nasution, Dewi Rosanti, Inka Dahlianah, Indobiosains, Volume 3 No. 1, Februari 2021, 31-37.

Suryaningsih, Joni M, dan Darmadi AAK. 2011. Inventarisasi Gulma pada Tanaman Jagung (Zea mays L.) di Lahan Sawah Kelurahan Padang Galak, Denpasar Timur, Kodya Denpasar, Provinsi Bali. Jurnal Simbiosis. 1(1): 1-13 hlm.

Suwarto. 2010. Budidaya Tanaman Unggulan Perkebunan. Penebar Swadaya. Jakarta. 